\title{
Theoretical Description for Sucralose Cathodical Electrochemical Determination on the Conducting Polymer, Containing Pyridinic Nitrogen Atoms
}

\author{
Volodymyr V. Tkach 1,2,* (D), Nataliia M. Storoshchuk ${ }^{1}$ (D), Bogdan D. Storoshchuk ${ }^{1}$ (D), \\ Vira V. Kopiika ${ }^{3}$ (D), Olga V. Luganska ${ }^{3}$ (D), Lyudmyla O. Omelyanchik ${ }^{3}$ (D), Viktoria I. Gencheva ${ }^{3}$ (D), \\ Yulia V. Yeshchenko ${ }^{3}$ (D), Zholt O. Kormosh ${ }^{4}$ (D), Yevgeniya V. Nazymok ${ }^{5}$ (D), \\ Volodymyr D. Moysiuk 5 (D), Vitalii F. Rusnak 5 (D), Yuriy I. Palichuk 1,5 (D), Vira M. Odyntsova 6 (D), \\ Volodymyr M. Omelyanchik ${ }^{6}$ (D), Karina V. Palamarek ${ }^{7}$ (D), Konon L. Bagrii ${ }^{7}$ (D), \\ Lyubov T. Strutynska $^{7}$ (D), Inna P. Danyliuk ${ }^{7}$ (D), Sílvio C. De Oliveira ${ }^{2}$ (D), Petro I. Yagodynets ${ }^{1, *}$ (D), \\ Dilafruz B. Razhabova 8 (D) \\ 1 Chernivtsi National University, 58000, Kotsyubyns 'ky Str. 2, Chernivtsi, Ukraine \\ 2 Universidade Federal de Mato Grosso do Sul, Av. Sen. Felinto. Müller, 1555, C/P. 549, 79074-460, Campo Grande, MS, \\ Brazil \\ 3 Zaporizhzhia National University, 69600, Zhukovsky Str. 66, Zaporizhzhia, Ukraine \\ 4 Eastern European National University, 43000, Voli Ave., 13, Lutsk, Ukraine \\ Bukovinian State Medical University, 58001, Teatralna Sq., 9, Chernivtsi Ukraine \\ Zaporizhzhia State Medical University, 69600, Mayakovsky Ave., 24, Zaporizhzhia, Ukraine \\ Chernivtsi Institute of Trade and Economics of Kyiv National University of Trade and Economics, 58012, Central Sq. 9 , \\ Chernivtsi, Ukraine \\ 8 Abu Ali Ibn Sino Bukhara State Medical Institute, 705018, Navoi Str., 1, Bukhara, Uzbekistan \\ * Correspondence: nightwatcher2401@gmail.com (V.V. T.); ved1988mid@ rambler.ru (P.I.Y.)
}

Scopus Author ID 55758299100

Received: 30.04.2021; Revised: 29.05.2021; Accepted: 2.06.2021; Published: 9.06.2021

\begin{abstract}
A novel process for sucralose cathodically electrochemical determination has been suggested. In this process, the conducting polymer with pyridinic nitrogen atoms reacts specifically with sucralose, yielding a salt. This salt is thereby reduced gradually, yielding a less conducting macromolecule. The analysis of the correspondent mathematical model, realized through the linear stability theory and bifurcation analysis, shows that the oscillatory behavior is more probable to be realized due to charge changes and rearrangements during the electroanalytical process its influence on the surface and DEL conductivity. Nevertheless, this process may be efficient for the sucralose electrochemical determination.
\end{abstract}

Keywords: sucralose; electrochemical sensor; conducting polymer; electrochemical oscillations; stable steady-state.

(C) 2021 by the authors. This article is an open-access article distributed under the terms and conditions of the Creative Commons Attribution (CC BY) license (https://creativecommons.org/licenses/by/4.0/).

\section{Introduction}

The chemically modified electrodes (CME) are one of the most modern and flexible tools in electroanalytical chemistry [1-4]. They provide a rapid, efficient, accurate and selective analyte determination due to their affinity to the analyte.

On the other hand, sucralose $[5,6]$ is one of the most-used sugar substitutes in the world. It is three times as sweeter as aspartame, twice as sweeter as saccharin, and 800 to 1000 times sweeter than sucrose $[7,8]$. 


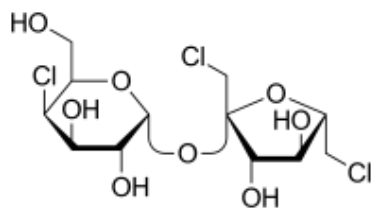

Figure 1. Sucralose.

It has been approved for use in the USA, in Canada, in Australia, and in the European Union [8]. Its chemical composition is related to that of carbohydrates. But, containing three chlorine atoms may present toxic effects like mutagenesis, carcinogenesis, provoke obesity, and growth of glucose levels [7-12]. Moreover, while stored in an inappropriate way, it may form dioxins, which are even more toxic compounds $[13,14]$.The sucralose decomposition during baking may lead to the chloropropanoles formation [15]. So, the development of an efficient method for sucralose detection is actual [16-18], and the use of electrochemical methods for it would be very interesting.

The possibility of electrochemical sucralose determination has already been foreseen by us theoretically $[19,20]$ and confirmed experimentally [21]. A direct electrooxidation of sucralose was used either in the model or in the experiment. In work [19], sucralose immobilization on an acridine derivative capable of forming a quaternary salt has been suggested. The sucralose immobilization was foreseen to be followed by the electrochemical oxidation of hydroxyl groups of the sucralose units. Another opportunity could be an electrochemical reduction of sucralose salt with the correspondent pyridinic nitrogen compound, yet realized for paraquat and diquat [22, 23].

Nonetheless, the novel electrode modifiers' relation to the analytes may include the problems of mechanism interpretation, like the need to explain the electrochemical instabilities, yet described for the electrooxidation and reduction of organic compounds [24-28].

The mentioned problems may only be solved by analyzing a mathematical model capable of adequately describing the fluoxetine electrochemical determination. Moreover, it is also capable of comparing this system's behavior with similar processes by theoretical means.

So this work is aimed to describe the sucralose electrochemical determination theoretically over a conducting polymer containing pyridinic nitrogen atoms. In order to realize it, we suggest the reaction mechanism, developing and analyzing the mathematical model based on it. Also, the system's behavior has to be compared with similar electrochemical processes [19-21].

\section{System and its Modeling}

In the first stage, the sucralose reacts with the polymer, yielding a quaternary salt (Fig. 2):

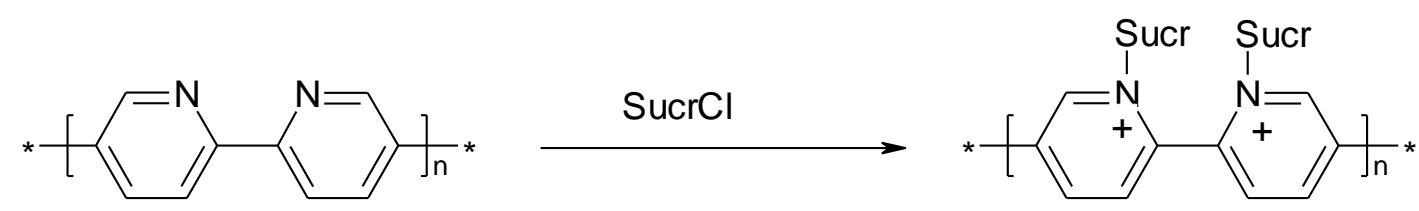

Figure 2. Quaternary salt formation

As the cathodic current is applied to the polymer, the conducting polymer is thereby reduced. The charge distribution is changed, and the double bond conjugated system is modified (Fig. 3): 


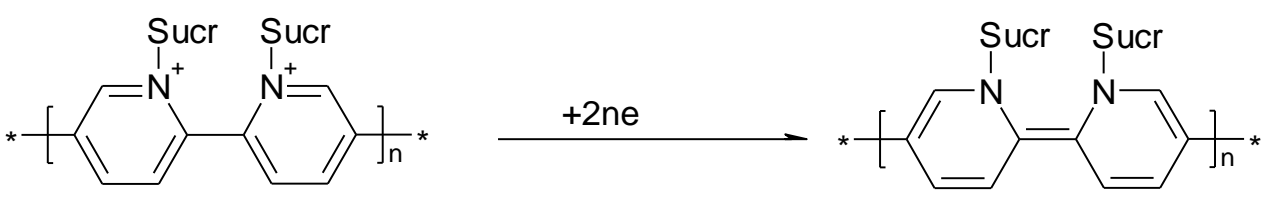

Figure 3. First electrochemical reduction stage

By this, the deformed conjugated material is non-aromatic and, therefore, can reduce, interrupting the bond system (Fig. 4).
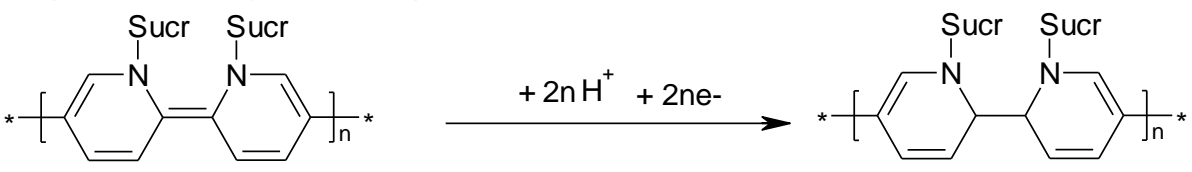

Figure 4. Second electrochemical reduction stage

As for the material conductivity increases in the first stage due to the salt formation and decreases in the chemical and electrochemical stages.

Taking into account the mentioned statements, we describe the behavior of this system by the trivariate balance differential equation set, formed by the variables:

$\mathrm{s}$ - sucralose concentration in the pre-surface layer;

$\mathrm{p}$ - polymer salt surface coverage degree;

$\mathrm{q}$ - quinonized polymer surface coverage degree.

Accepting certain assumptions [28], we describe the behavior of this system will be described by three balance equations, written as (1):

$$
\left\{\begin{array}{c}
\frac{d s}{d t}=\frac{2}{\delta}\left(\frac{\Delta}{\delta}\left(s_{0}-s\right)-r_{s}\right) \\
\frac{d p}{d t}=\frac{1}{P}\left(r_{s}-r_{r 1}\right) \\
\frac{d q}{d t}=\frac{1}{Q}\left(r_{r 1}-r_{r 2}\right)
\end{array}\right.
$$

Herein, $\mathrm{s}_{0}$ is the sucralose bulk concentration, $\mathrm{P}$ and $\mathrm{Q}$ are corresponding polymeric forms maximal surface concentrations, and the parameters $r$ are the corresponding reaction rates, calculated as:

$$
\begin{gathered}
r_{s}=k_{s} s^{2 n}(1-p-q) \exp (-a s)(2) \\
r_{r 1}=k_{r 1} p \exp \left(-\frac{2 n F \varphi_{0}}{R T}\right) \\
r_{r 2}=k_{r 2} q \exp \left(-\frac{2 n F \varphi_{0}}{R T}\right)
\end{gathered}
$$

Herein, the parameters $\mathrm{k}$ are the correspondent rate constants, $\mathrm{a}$ is the variable describing the chemical stage influence to the DEL and surface conductivity, $\mathrm{n}$ is the polymer chain length, $\mathrm{F}$ is the Faraday number, $\varphi_{0}$ is the potential slope, related to the zero-charge potential, $\mathrm{R}$ is the universal gas constant, and $\mathrm{T}$ is the absolute temperature.

As all of the three stages, which compose the process, influence the double electric layer, the oscillatory and monotonic instabilities are capable of realizing with more probability. Nevertheless, the electroanalytical process will remain efficient, as shown below.

\section{Results and Discussion}

In order to describe the behavior of the electrochemical system with sucralose cathodically determination over a conducting polymer with pyridinic nitrogen, we analyze the equation-set (1) by means of linear stability theory. The steady-state Jacobian matrix members for this system will be described as (5): 
where:

$$
\left(\begin{array}{lll}
a_{11} & a_{12} & a_{13} \\
a_{21} & a_{22} & a_{23} \\
a_{31} & a_{32} & a_{33}
\end{array}\right)
$$

$$
\begin{aligned}
& a_{11}=\frac{2}{\delta}\left(-\frac{\Delta}{\delta}-2 n k_{s} s^{2 n-1}(1-p-q) \exp (-a s)+a k_{s} s^{2 n}(1-p-q) \exp (-a s)\right) \\
& a_{12}=\frac{2}{\delta}\left(k_{s} s^{2 n} \exp (-a s)\right) \\
& a_{13}=\frac{2}{\delta}\left(k_{s} s^{2 n} \exp (-a s)\right) \\
& a_{21}=\frac{1}{P}\left(2 n k_{s} s^{2 n-1}(1-p-q) \exp (-a s)-a k_{s} s^{2 n}(1-p-q) \exp (-a s)\right)(9) \\
& a_{22}=\frac{1}{P}\left(-k_{s} s^{2 n} \exp (-a s)-k_{r 1} \exp \left(-\frac{2 n F \varphi_{0}}{R T}\right)+j k_{r 1} p \exp \left(-\frac{2 n F \varphi_{0}}{R T}\right)\right)(10) \\
& a_{23}=\frac{1}{P}\left(-k_{S} s^{2 n} \exp (-a s)-l k_{r 1} p \exp \left(-\frac{2 n F \varphi_{0}}{R T}\right)\right) \\
& a_{31}=0 \\
& a_{32}=\frac{1}{Q}\left(k_{r 1} \exp \left(-\frac{2 n F \varphi_{0}}{R T}\right)+j k_{r 1} p \exp \left(-\frac{2 n F \varphi_{0}}{R T}\right)\right) \\
& a_{33}=\frac{1}{Q}\left(-l k_{r 1} p \exp \left(-\frac{2 n F \varphi_{0}}{R T}\right)-k_{r 2} \exp \left(-\frac{2 n F \varphi_{0}}{R T}\right)+l k_{r 2} q \exp \left(-\frac{2 n F \varphi_{0}}{R T}\right)\right)
\end{aligned}
$$

Taking into account the main diagonal elements (6), (10), and (14), we may conclude that the oscillatory behavior, in this case, is possible. Moreover, it will be more probable than for similar systems due to the somehow more expressive influence of all three reaction stagers to double the electric layer and surface conductivity and resistance.

These elements are $l k_{r 2} q \exp \left(-\frac{2 n F \varphi_{0}}{R T}\right)>0$ if $1>0, j k_{r 1} p \exp \left(-\frac{2 n F \varphi_{0}}{R T}\right)>0$ if $\mathrm{j}>0$, describing the DEL influences of two electrochemical stages, and $a k_{s} s^{2 n}(1-p-$ $q) \exp (-a s)>0$ if $a>0$, describing the analogous influences of the chemical stage.

The oscillations' frequency and amplitude are dependent on the background electrolyte composition, directly related to DEL structure and conductivity. Nevertheless, the proper oscillations are expected to be frequent and of small amplitude.

In order to apply the Routh-Hurwitz criterion without cumbersome expressions, we rewrite the matrix determinant as (15):

$$
\frac{2}{\delta N_{1} N_{2}}\left|\begin{array}{ccc}
-\kappa-\Xi & \Sigma & \Sigma \\
\Xi & -\Gamma-\Sigma & -T-\Sigma \\
0 & -\Phi-\Gamma & -\Omega-T-\Sigma
\end{array}\right|
$$

Opening the brackets and applying the requisite Det $\mathrm{J}<0$, salient from the criterion, we obtain the steady-state stability condition, exposed as:

$$
-\kappa\left(\Gamma \Omega+\Sigma \Omega+\Sigma T+\Sigma^{2}-\Phi T-\Phi \Sigma\right)-\Xi(\Gamma \Omega+\Sigma \Omega+\Sigma T-\Phi T+\Phi \Sigma)<0
$$

This describes an electroanalytical efficient process, which is either diffusion or kinetically controlled. The transition to diffusion- or kinetically controlled mode is realized by changing the electrolyte composition, analyte concentration, and electrode shape.

The steady-state stability topological zone has to be narrower than in the more simple cases described in [19-21]. Nevertheless, it remains relatively wide, providing a wide concentration interval of sensitive sucralose determination. As no side reactions capable of compromising the analyte or modifier stability are typical for this case, the steady-state stability will correspond to the linear dependence between the analyte concentration and electrochemical parameter. 
As for the detection limit, it will be described by the monotonic instability. It delimits the stable steady-states from unstable states, and its condition will be Det $\mathrm{J}=0$, or (17):

$$
-\kappa\left(\Gamma \Omega+\Sigma \Omega+\Sigma T+\Sigma^{2}-\Phi T-\Phi \Sigma\right)-\Xi(\Gamma \Omega+\Sigma \Omega+\Sigma T-\Phi T+\Phi \Sigma)=0
$$

Also, if the reaction is realized in acidic media, sucralose fragment tends to dehalogenize, yielding a chloride ion. By this, the model will be transformed into (18):

$$
\left\{\begin{array}{c}
\frac{d s}{d t}=\frac{2}{\delta}\left(\frac{\Delta}{\delta}\left(s_{0}-s\right)-r_{s}\right) \\
\frac{d p}{d t}=\frac{1}{P}\left(r_{s}-r_{r 1}\right) \\
\frac{d q}{d t}=\frac{1}{Q}\left(r_{r 1}-r_{r 2}-r_{d}\right)
\end{array}\right.
$$

where $r_{d}$ is the dehalogenation rate, described as:

$$
r_{d}=k_{d} q \exp \left(-\frac{4 n F \varphi_{0}}{R T}\right)
$$

As a chloride ion is formed during the dehalogenation, the membrane, impeding the chlorine evolution (20)

$$
2 \mathrm{Cl}^{-}-2 \mathrm{e}^{-} \rightarrow \mathrm{Cl}_{2}(20)
$$

will be installed in order to separate the cathodic and anodic solutions. By this, the dehalogenation cell will be designed as in Figure 5:

\section{Membrane}

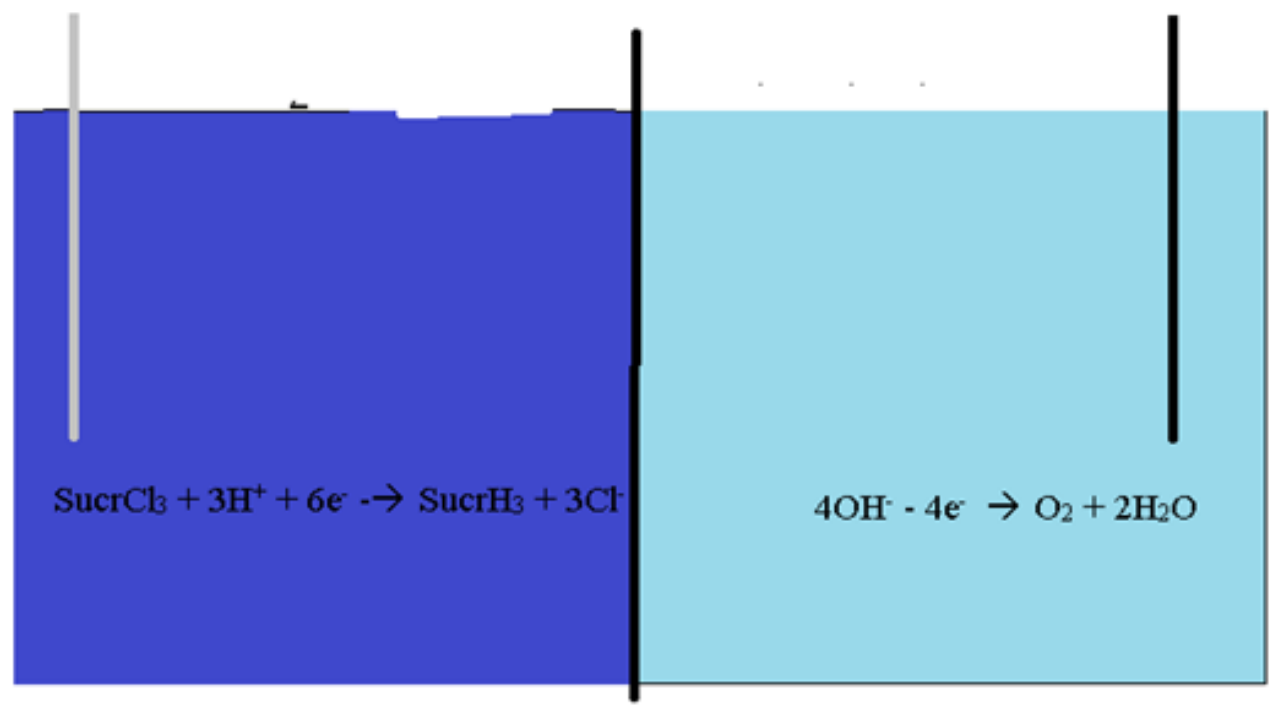

Figure 5. Sucralose dehalogenation cell.

The process will be thereby similar to [28]. The membrane is made of polyvinyl pyridines (PVP), which retain the chloride-ion by salt formation (Fig. 6):

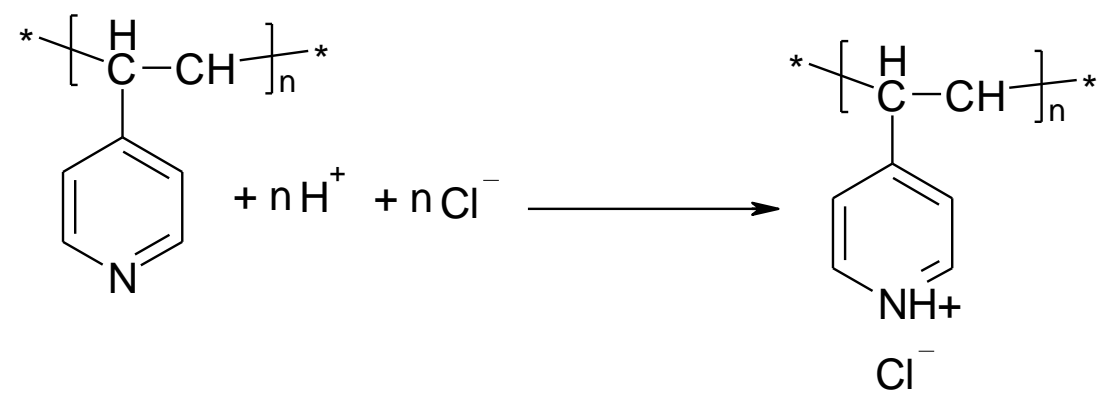

Figure 6. Chlorine retention by PVP membrane 
As for the membrane regeneration, it is realized as on the Figure 7:<smiles>CC(C)(C)C(c1cc[nH+]cc1)C(C)(C)C</smiles>
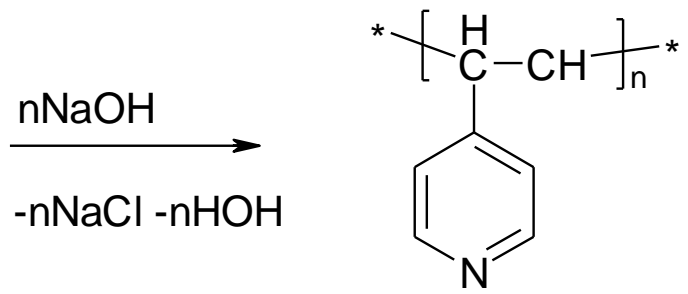

Figure 7. Membrane regeneration

By maintenance of the sucralose elimination process, membrane confection, and regeneration rhythms, an economical and green sucralose elimination process is conducted.

\section{Conclusions}

From the theoretical description of sucralose electrochemical determination over a conducting polymer containing the pyridinic nitrogen, it has been possible to conclude that the mechanism consists of the chemical and two gradual electrochemical stages, leading to the appearance of a determined analytical signal. The polymer may serve as an excellent modifier for sucralose quantification. The stable steady-state is maintained easily. The system is electroanalytical efficient. Depending on the electrolyte composition, electrode size, and the analyte concentration, the process may be diffusion- or kinetically controlled. The oscillatory behavior in this system is possible, being caused only by DEL influences of both electrochemical processes, like also of the chemical stage.

\section{Funding}

This research received no external funding.

\section{Acknowledgments}

\section{This research has no acknowledgment.}

\section{Conflicts of Interest}

The authors declare no conflict of interest.

\section{References}

1. Kumar, Y.; Vashistha, V.K.; Das, D.K. Synthesis of Perovskite-type $\mathrm{NdFeO}_{3}$ nanoparticles and used as electrochemical sensor for detection of paracetamol. Lett. Appl. Nanobiosci. 2020, 9, 866-869, https://doi.org/10.33263/LIANBS91.866869.

2. Joshi, N.Ch; Malik, Sh.; Gururani, Pr. Utilization of Polypyrrole/ZnO Nanocomposite in the Adsorptive Removal of $\mathrm{Cu}^{2+}, \mathrm{Pb}^{2+}$ and $\mathrm{Cd}^{2+}$ Ions from Wastewater. Lett. Appl. Nanobiosci. 2021, 10, 2339-2351, https://doi.org/10.33263/LIANBS103.23392351.

3. Fernandes-Junior, W.S.; Zaccarin, L.F.; Oliveira, G.G.; de Oliveira, P.R.; Kalinke, C.; Bonacin, J.A.; Prakash, J.; Janegitz, B.C. Electrochemical Sensor Based on Nanodiamonds and Manioc Starch for Detection of Tetracycline. Journal of Sensors 2021, 2021, 6622612, https://doi.org/10.1155/2021/6622612.

4. Jahani, P.M.; Javar, H.A; Mahmoudi-Moghaddam, H. A new electrochemical sensor based on Europiumdoped $\mathrm{NiO}$ nanocomposite for detection of venlafaxine. Measurement 2021, 173, 108616, https://doi.org/10.1016/j.measurement.2020.108616. 
5. Greenhill, C. Metabolic effects of sucralose. Nat Rev Endocrinol. 2020, 16, 256-257, https://doi.org/10.1038/s41574-020-0348-6.

6. Naik, A.Q; Zafar,T; Shrivastava, V.K. Environmental Impact of the Presence, Distribution, and Use of Artificial Sweeteners as Emerging Sources of Pollution.J. Env. Publ. Health 2021, 2021, 6624569, https://doi.org/10.1155/2021/6624569.

7. Bórquez, J.C.; Hidalgo, M.; Rodríguez, J.M.; Montaña, A.; Porras, O.; Troncoso, R.; Bravo-Sagua, R. Sucralose Stimulates Mitochondrial Bioenergetics in Caco-2 Cells. Frontiers in Nutrition 2021, 7, 361, https://doi.org/10.3389/fnut.2020.585484.

8. Yang, Y.; Liu, Z.; Zheng, H.; Zhu, S.; Zhang, K.; Li, X.; Ma, X.; Dietrich, A.M. Sucralose, a persistent artificial sweetener in the urban water cycle: insights into occurrence, chlorinated byproducts formation, and human exposure. Journal of Environmental Chemical Engineering 2021, 9, 105293, https://doi.org/10.1016/j.jece.2021.105293.

9. Yu, Z.; Wang, Y.; Lu, J.; Bond, P.L.; Guo, J. Nonnutritive sweeteners can promote the dissemination of antibiotic resistance through conjugative gene transfer. The ISME Journal 2021,https://doi.org/10.1038/s41396-021-00909-x.

10. Rosales-Gómez, C.A.; Martínez-Carrillo, B.E.; Reséndiz-Albor, A.A.; Ramírez-Durán, N.; Valdés-Ramos, R.; Mondragón-Velásquez, T.; Escoto-Herrera, J.A. Chronic Consumption of Sweeteners and Its Effect on Glycaemia, Cytokines, Hormones, and Lymphocytes of GALT in CD1 Mice. BioMed Research International 2018, 2018, 1345282,https://doi.org/10.1155/2018/1345282.

11. Harpaz, D.; Yeo, L.P.; Cecchini, F.; Koon, T.H.P.; Kushmaro, A.; Tok, A.I.Y.; Marks, R.S.; Eltzov, E. Measuring Artificial Sweeteners Toxicity Using a Bioluminescent Bacterial Panel. Molecules 2018, 23, https://doi.org/10.3390/molecules23102454.

12. Ahmad, S.Y.; Friel, J.K; Mackay, D.S. Effect of sucralose and aspartame on glucose metabolism and gut hormones, Nutr. Rev. 2020, 78, 725-746, https://doi.org/10.1093/nutrit/nuz099.

13. Dalenberg, J.R.; Patel, B.P.; Denis, R.; Veldhuizen, M.G.; Nakamura, Y.; Vinke, P.C.; Luquet, S.; Small, D.M. Short-term consumption of sucralose with, but not without, carbohydrate impairs neural and metabolic sensitivity to sugar in humans. Cell Metab. 2020, 31, 493-502, https://doi.org/10.1016/j.cmet.2020.01.014.

14. Bueno-Hernández, N.; Esquivel-Velázquez, M.; Alcántara-Suárez, R.; Gómez-Arauz, A.Y.; Espinosa-Flores, A.J.; de León-Barrera, K.L.; Mendoza-Martínez, V.M.; Sánchez Medina, G.A.; León-Hernández, M.; RuizBarranco, A.; Escobedo, G.; Meléndez, G. Chronic sucralose consumption induces elevation of serum insulin in young healthy adults: a randomized, double blind, controlled trial. Nutr. J. 2020, 19, 32, https://doi.org/10.1186/s12937-020-00549-5.

15. El-Hage, R.; El-Hellani, A.; Haddad, C.; Salman, R.; Talih, S.; Shihadeh, A.; Eissenberg, T.; Aoun Saliba, N. Toxic emissions resulting from sucralose added to electronic cigarette liquids. Aerosol Sci. Technol. 2019, 53, 1197-1203,https://doi.org/10.1080/02786826.2019.1645294.

16. Neves, N; Ribeiro, N; Esteves, C.; Barros, P. Determination of Sweeteners in Wine by Liquid Chromatography, Coupled with Mass Spectrometry (LC/MS)Ciên. Tecn. Vitivinícola 2021, 36, 32-44, https://doi.org/10.1051/ctv/ctv2021360132.

17. Diviš, P.; Jurečková, Z.; Vespalcová, M.; Pořízka, J.; Punčochářová, L. Simultaneous determination of sweeteners and preservatives in beverages by HPLC-DAD-ELSD. Potravinarstvo Slovak Journal of Food Sciences 2020, 14, 881-886, https://doi.org/10.5219/1339.

18. Sonamit, K; Vitchaivutivong, S.; Harntaweesup, Y. Method Validation for Determination of Sucralose in Soft Beverages by UPLC-ELSD.Bull. Dep. Med. Sci. 2019, 61, 107-120, https://he02.tcithaijo.org/index.php/dmsc/article/view/240705.

19. Tkach, V.V.; Kushnir, M.V.; de Oliveira, S.C.; e Gala, H.B.; Luganska, O.V.; Lukanova, S.M.; Yagodynets, P.I. The mathematical description for sucralose electrochemical detection on the novel acridinic derivative. Applied Journal of Environmental Engineering Science 2018, 4, 42,https://doi.org/10.48422/IMIST.PRSM/ajees-v4i2.11583.

20. Tkach, V.V.; Kukovs'ka, I.L.; Lukanova, S.M.; Boychuk, O.M.; Yurchuk, L.P.; Stefanchuk, V.I.; Khashchuk, V.S.; de Oliveira, S.C.; Ojani, R.; Yagodynets, P.I. The Mathematical Description for Sucralose Electrochemical Detection on the Overoxidized Polypyrrole. Analytical and Bioanalytical Electrochemistry 2018, 10, 587-593,https://www.sid.ir/en/journal/ViewPaper.aspx?ID=659807.

21. Bathinapatla, A.; Kanchi, S.; Sabela, M.I.; Ling, Y.C.; Bisetty, K.; Inamuddin. Experimental and Computational Studies of a Laccase Immobilized ZnONPs/GO-Based Electrochemical Enzymatic Biosensor 
for the Detection of Sucralose in Food Samples. Food Analytical Methods 2020, 13, 2014-2027, https://doi.org/10.1007/s12161-020-01824-1.

22. Laghrib, F.; Bakasse, M.; Lahrich, S.; El Mhammedi, M.A. Electrochemical sensors for improved detection of paraquat in food samples: A review. Materials Science and Engineering: C 2020, 107, 110349, https://doi.org/10.1016/j.msec.2019.110349.

23. El Ouafy, H.; El Ouafy, T.; Oubenali, M.; El Idrissi, M.; Echajia, M.; Haimouti, A.E.L.; Mbarki, M.; Oulfajrite, H. Electroanalysis of the herbicide diquat by electrochemical detector containing particles of clay in environmental water. Analytical and Bioanalytical Electrochemistry 2020, 12, 168-179, http://www.abechem.com/article_38584.html.

24. Das, I.; Goel, N.; Agrawal, N.R.; Gupta, S.K. Growth patterns of dendrimers and electric potential oscillations during electropolymerization of pyrrole using mono-and mixed surfactants. 2010, 114, 12888-12896, https://doi.org/10.1021/jp105183q.

25. Das, I.; Goel, N.; Gupta, S.K.; Agrawal, N.R. Electropolymerization of pyrrole: Dendrimers, nano-sized patterns and oscillations in potential in presence of aromatic and aliphatic surfactants. Journal of Electroanalytical Chemistry 2012, 670, 1-10, https://doi.org/10.1016/j.jelechem.2012.01.023.

26. Alshahrani, L.A.; Miao, L.; Zhang, Y.; Cheng, S.; Sathishkumar, P.; Saravanakumar, B.; Nan, J.; Gu, F.L. 3D-Flower-Like Copper Sulfide Nanoflake-Decorated Carbon Nanofragments-Modified Glassy Carbon Electrodes for Simultaneous Electrocatalytic Sensing of Co-existing Hydroquinone and Catechol. Sensors 2019, 19, https://doi.org/10.3390/s19102289.

27. Malakootian, M.; Hamzeh, S.; Mahmoudi-Moghaddam, H. A Novel Electrochemical Sensor Based on $\mathrm{FeNi}_{3} / \mathrm{CuS} / \mathrm{BiOCl}$ Modified Carbon Paste Electrode for Determination of Bisphenol A.Electroanalysis, 2020, 32, 205, https://doi.org/10.1002/elan.2020060205.

28. Tkach, V.V.; Kushnir, M.V.; de Oliveira, S.C.; Ivanushko, Y.G.; Tkach, V.O.; Mytrofanova, H.Y.; Zadoia, A.O.; Yagodynets, P.I.; Kormosh, Z.O.; Luganska, O.V. Theoretical Description for Copper (II) Electrochemical Determination and Retention on a 1 (2-pyridilazo)-2-naphthole-Modified Anode.Lett. Appl. NanoBioSci. 2021, 10, 2078-2084, https://doi.org/10.33263/LIANBS102.20782084. 